\title{
Validation of JAXA/MODIS Sea Surface Temperature in Water around Taiwan Using the Terra and Aqua Satellites
}

\author{
Ming-An Lee ${ }^{1,2}$, Mu-Tun Tzeng ${ }^{1}$, Kohtaro Hosoda ${ }^{3}$, Futoki Sakaida ${ }^{3}$, Hiroshi Kawamura ${ }^{3}$, \\ Wei-Juan Shieh ${ }^{2}$, Yih Yang ${ }^{2}$, and Yi Chang ${ }^{1, *}$ \\ ${ }^{1}$ Department of Environmental Biology and Fisheries Science, National Taiwan Ocean University, Keelung, Taiwan, ROC \\ ${ }^{2}$ Taiwan Ocean Research Institute, National Applied Research Laboratories, Taipei, Taiwan, ROC \\ ${ }^{3}$ Ocean Environment Group, Center for Atmospheric and Oceanic Studies, Graduate School of Science, \\ Tohoku University, Miyagi, Japan 980-8578
}

Received 23 March 2009, accepted 7 September 2009

\begin{abstract}
The research vessel-based Conductivity Temperature Depth profiler (CTD) provides underwater measurements of the bulk sea surface temperature (SST) at the depths of shallower than $5 \mathrm{~m}$. The CTD observations of the seas around Taiwan provide useful data for comparison with SST of MODIS (Moderate Resolution Imaging Spectroradiometers) aboard Aqua and Terra satellites archived by JAXA (Japan Aerospace Exploration Agency). We produce a high-resolution (1 km) MODIS SST by using Multi-Channel SST (MCSST) algorithm. There were 1516 cloud-free match-up data pairs of MODIS SST and in situ measurements during the period from 2003 - 2005. The difference of the root mean square error (RMSE) of satellite observations from each platform during the day and at night was: $0.88^{\circ} \mathrm{C}$ in Aqua daytime, $0.71^{\circ} \mathrm{C}$ in Aqua nighttime, $0.71^{\circ} \mathrm{C}$ in Terra daytime, and $0.60^{\circ} \mathrm{C}$ in Terra nighttime. The total analysis of MODIS-derived SST shows good agreement with a bias of $0.03^{\circ} \mathrm{C}$ and RMSE of $0.75^{\circ} \mathrm{C}$. The analyses indicate that the bias of Aqua daytime was always positive throughout the year and the large RMSE should be attributed to the large positive bias $\left(0.45^{\circ} \mathrm{C}\right)$ under diurnal warming. It was also found that the bias of Terra daytime was usually negative with a mean bias of $-0.41^{\circ} \mathrm{C}$; its large RMSE should be treated with care because of low solar radiation in the morning.
\end{abstract}

Key word: SST, Taiwan, MODIS, Satellite observation

Citation: Lee, M. A., M. T. Tzeng, K. Hosoda, F. Sakaida, H. Kawamura, W. J. Shieh, Y. Yang, and Y. Chang, 2010: Validation of JAXA/MODIS sea surface temperature in water around Taiwan using the Terra and Aqua satellites. Terr. Atmos. Ocean. Sci., 21, 727-736, doi: 10.3319/TAO.2009.09.07.01(Oc)

\section{INTRODUCTION}

With the launch of technologically advanced and innovative satellite instruments like AVHRR (Advanced Vary High Resolution Radiometer) and MODIS (Moderate Resolution Imaging Spectroradiometer) high resolution sea surface temperature (SST) data are provided for atmospheric and oceanic observations. Satellite retrieved SST data using infrared sensor from AVHRR have been used for many years and well validated for open ocean and coastal water observation. Sakaida and Kawamura (1992) and Shenoi (1999) showed that the use of regional SST retrieval algorithms from AHVRR observations has a lower root mean square error (RMSE) than respective global algorithms in

\footnotetext{
* Corresponding author

E-mail:jeche7058@msn.com
}

the western North Pacific and northern Indian oceans. Lee et al. (2005) indicated that MCSST (Multi-Channel Sea Surface Temperature; McClain et al. 1985) algorithm retrieved SSTs was in good agreement with in situ measurements of the coastal water around Taiwan with RMSE of $0.64^{\circ} \mathrm{C}$.

After MODIS sensors were launched on 18 December 1999 (Terra) and 4 May 2002 (Aqua), geophysical observations have been continued to the present. Compared with the AVHRR SST, Goodrum et al. (2000) suggested that the noise equivalent temperature difference (NEdT) of MODIS $11 \mu \mathrm{m}$ band is $0.05 \mathrm{~K}$, which was a considerable improvement over that of AVHRR (NEdT = 0.12 K). Wan (2002) also indicated that the standard deviation of early on-orbit observations of MODIS $11 \mu \mathrm{m}$ band is no greater than $0.05 \mathrm{~K}$. In addition, many bands observed by MODIS yield 
more accurate atmospheric correction and cloud screening. It is therefore anticipated that clear SST fields are obtained from MODIS sensors. The MODIS SSTs processed at the Japan Aerospace Exploration Agency/Earth Observation Research Center (JAXA/EORC) are expected to be more accurate than those estimated from the global algorithm for MODIS because they are retrieved from a regional SST algorithm that is adjusted to the western North Pacific water (Hosoda et al. 2007). Hosoda et al. (2007) retrieved MODIS SST from the JAXA/EORC ocean products around Japan to develop and validate in situ measurements by drifting buoys. They indicated that the SST retrieved from their newly developed near real time MCSST algorithm was more accurate than that retrieved from a global algorithm.

The MODIS SST products from the Aqua/Terra satellites are a composite to produce full spatial coverage at $1 \mathrm{~km}$ resolution. This increased resolution adds much finer scale structure to the SST fields as boundary conditions for oceanic front modeling and air-sea interaction in the costal water around Taiwan (Li et al. 2006; Chang et al. 2008). However, the validation of SST retrieved from MODIS in the coastal and shelf regions around Taiwan has not been well studied because it is quite exceptional for drifting buoy flows to coastal region, especially in the Taiwan Strait. For this reason, it is difficult to have enough buoy data to validate the satellite-derived SST in the coastal and shelf waters around Taiwan. Therefore, the data sets available from field observing instrument performed by local research vessels could be used for validation work. Oceanic research vessels have routinely collected CTD data since the 1980s in the water around Taiwan (e.g., Chuang 1985; Jan et al. 2002). Lee et al. (2005) validated the AVHRR/SST with the CTD measurements. They averaged the water temperature of the top $5 \mathrm{~m}$ as the "bulk SST" and showed good agreement with AVHRR/SST and bulk SST. We thus considered that CTD data can provide us with sufficient in situ measurements of water temperature to validate MODIS SST in our study area. Our purpose is to describe the validation of the MODIS SST with CTD measured water temperature in the waters around Taiwan. The present paper is an effort to assess the accuracies of SST retrieved from MODIS in comparison with ship based CTD observations. These in situ CTD measurements were collected by research vessels in the waters around Taiwan during the period of 2003 to 2005. Section 2 provides information on the data and algorithm used in this study. Section 3 presents the validation result of the algorithm. Finally, we discuss and summarize this study in sections 4 and 5 respectively.

\section{DATA AND METHOD}

\subsection{In Situ Data}

Traditionally, in situ SST measured by buoys within $1 \mathrm{~m}$ is used for validating the satellite-derived SST. This is impractical in the present study because it is rare to have a drifting buoy flow in the waters around Taiwan especially for the Taiwan Strait and coastal waters near Taiwan. Oceanic research vessels have routinely collected CTD data since the 1980s in our study area (Chuang 1985). Therefore, the CTD data are readily available for the validation of satellite-derived SST.

The routinely-calibrated CTD data collected by R/V Ocean Researcher I, II, and III were used to compare with the satellite SST measurements. Its measurement and accuracy ranged from -5 to 35 and $0.001{ }^{\circ} \mathrm{C}$, respectively. The CTD data were archived at the Ocean Data Bank (ODB), National Center for Ocean Research (NCOR). From January 2003 to May 2005, there were a total of 4751 CTD points (stations) of shipboard measurements in this study area (Fig. 1, $116-126^{\circ} \mathrm{E}$ and $20-30^{\circ} \mathrm{N}$ ). During our survey, the seawater at a depth of less than $5 \mathrm{~m}$ was selected and then water temperature was measured by the CTD, while the longitude and latitude of the station were positioned by the GPS (Global Positioning System). We examined the vertical variation of temperature for the top $5 \mathrm{~m}$. Figure 2 shows the examples from four cruises in 2003, and the difference between temperature at each meter and the top $5 \mathrm{~m}$ average were generally small. It is clear to see that this difference varied between -0.1 to $0.1^{\circ} \mathrm{C}$. Hence it is evident that the averaged temperature of the top $5 \mathrm{~m}$ can be a reliable bulk SST for the MODIS validation in this paper, and therefore the in situ CTD are representatives of the "bulk SST" for the further process of match-up data with MODIS SST.

\subsection{Satellite Data}

Two sun-synchronous satellites, Terra and Aqua, carry MODIS, which are visible and infrared radiometers. These satellites are $705 \mathrm{~km}$ from the Earth's surface and $\pm 55^{\circ}$ scanning covers a $2330 \mathrm{~km}$ swath, thereby providing global coverage. Terra has a descending pass in the morning (09:00 to 10:00) and at night (20:00 to 21:00), while Aqua has an ascending pass in the afternoon (12:00 to 13:00) and at midnight (01:00 to 02:00). In all, MODIS had 36 spectral bands ranging from $0.4-14.4 \mu \mathrm{m}$. Two bands were imaged at a resolution of $250 \mathrm{~m}$ at nadir, with five bands at $500 \mathrm{~m}$; the resolution of the remaining 29 bands was $1 \mathrm{~km}$. To retrieve SST, bands with a spatial resolution of $1 \mathrm{~km}$ were used. At the Japan Aerospace Exploration Agency/Earth Observation Research Center (JAXA/EORC), ocean products around Taiwan derived from MODIS are processed in near-real-time and are accessible via the Internet. The images and data with acquisition time (UTC time in minutes) are available within a few hours after their observation. The ground station for receiving MODIS data is Tokai University Space Information Center (TSIC; $32.8^{\circ} \mathrm{N}, 130.9^{\circ} \mathrm{E}$, from April 2001) and the JAXA/EORC $\left(36.0^{\circ} \mathrm{N}, 139.3^{\circ} \mathrm{E}\right.$, from August 2004). 


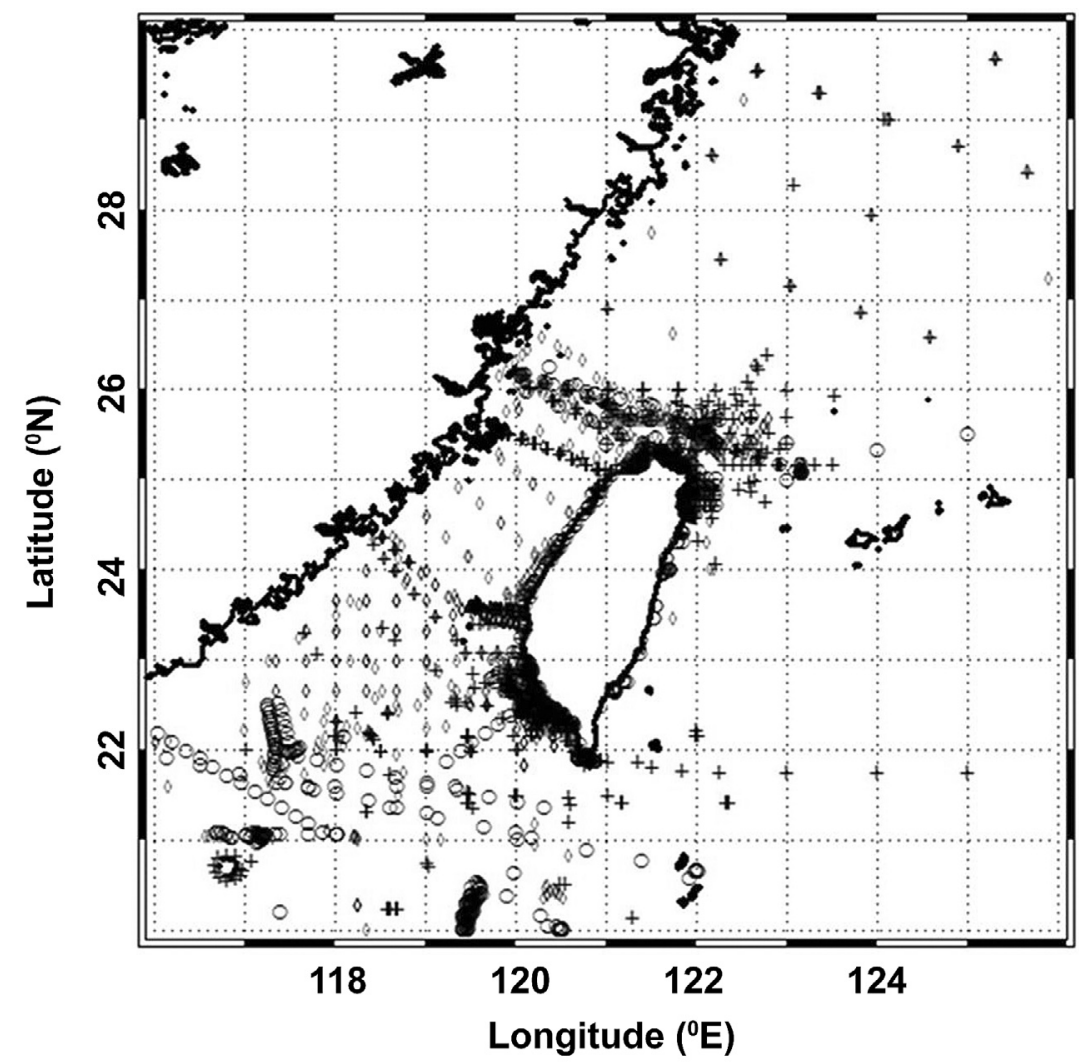

Fig. 1. Study area and the location of CTD observations during the period of $2003-2005(\diamond: 2003$, with 2172 points; +: 2004 , with 1531 points; O: 2005 , with 1048 points).

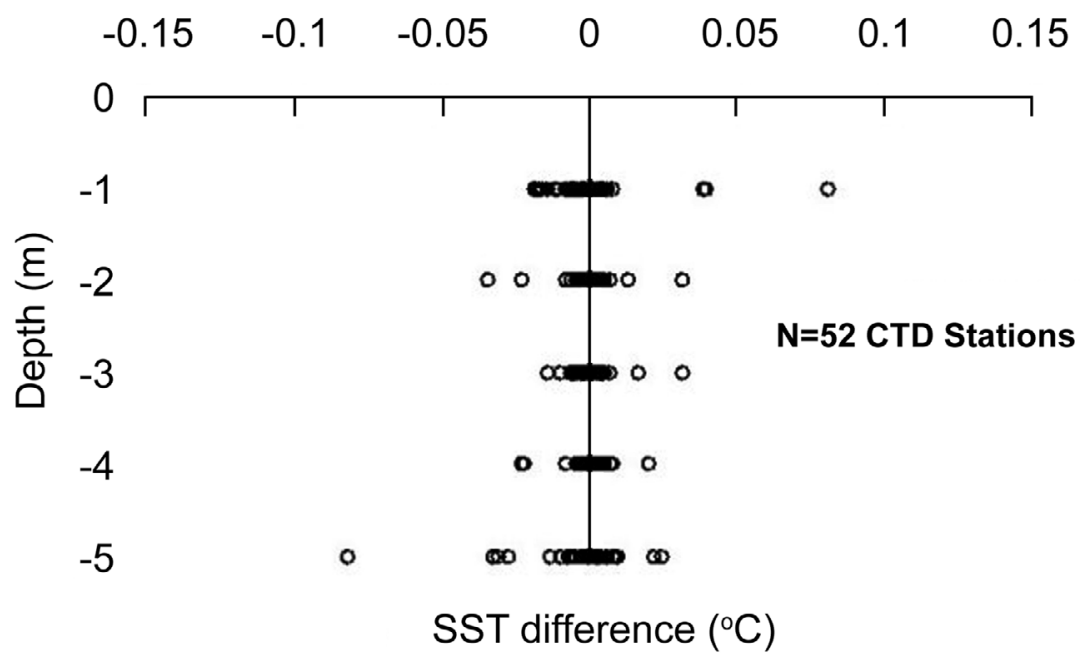

Fig. 2. The difference between the temperature at each meter and the average temperature of the top $5 \mathrm{~m}$ from four cruises in 2003.

The algorithm for retrieving near-real-time SST from MODIS in JAXA/EORC is based on the version 2 of Hosoda (2004). In this algorithm, the regional MCSST method was employed for atmospheric attenuation correction. Processing the retrieved SST, cloud detection schemes were improved based on Level 1B MODIS images from January 2003 to May 2005. The MODIS SST algorithm is defined as below:

$$
\begin{aligned}
\mathrm{SST}= & a 0+a 1 B T_{11}+\sum_{\lambda=3.7,8.7,12} \alpha_{\lambda} \overline{B T_{11}-B T_{\lambda}} \\
& +\sum_{\lambda=3.7,8,7,12} \beta_{\lambda} \overline{B T_{11}-B T_{\lambda}}\left(\sec \theta_{s z a}-1\right)
\end{aligned}
$$


where $B T_{\lambda}$ denotes a brightness temperature (Kelvin) at wavelength $\lambda \mu \mathrm{m}$ ( $\lambda$ is central wave length of each band); $\sec \theta_{s z a}$ is the secant of the satellite zenith angle $\theta$. The constant coefficients $a 0, a 1, \alpha_{\lambda}$, and $\beta_{\lambda}$ are shown in Table 1 (Hosoda et al. 2007). It is emphasized that this equation provides SST estimation in Kelvin.

\subsection{Match-Up Data}

In order to compare the satellite-derived SSTs with the in situ SSTs, we produced pairs of co-located satellite and in situ SST observations with time differences shorter than 24 hours. The match-up is comprised two major processes: precise image registration, and quality control. For example, in Fig. 3a the original MODIS SST image shows the significant projection error along the eastern coast of Taiwan, thus this image was remapped to an equirectangular projection with a grid size of $0.01^{\circ}$ to fit the geography (Fig. 3b). Among the total of 2826 MODIS images used in this study, 218 images had such a navigation problem and have been registered manually by visually examining each, before the match-up precession. From January 2003 to May 2005, the total number of match-up data contained 4369 corresponding daytime or nighttime match-up data sets. In the second step, four categories of match-up data sets have been classified. Figure 4 shows the four categories and examples. In the example images, a black point denotes the CTD observation site. The four categories are as follows: (1) cloud-free data (787 match-ups: Fig. 4a), (2) near the front (729 match-ups: Fig. 4b), (3) coastal observation (1763 match-ups: Fig. 4c), and (4) cloudy data (1090 match-ups: Fig. 4d). After classification, data sets of cloud-free and near front were used for calculating SST differences between CTD and its center pixel value in MODIS image. Among the obtained data sets, 1516 pairs classified as cloud-free and near front categories were used for further validation.

\section{RESULT}

The comparison illustrated that MODIS SSTs corresponded linearly with in situ SSTs (Fig. 5), in which bias is defined as MODIS SSTs minus in situ SSTs. During the day, MODIS observations onboard the Aqua satellite (Fig. 5a) showed larger positive bias $\left(0.58^{\circ} \mathrm{C}\right)$ in the warm temperature range $\left(>22^{\circ} \mathrm{C}\right)$, while the MODIS SSTs had small negative bias at night $\left(-0.12^{\circ} \mathrm{C}\right.$, Fig. 5 b). On the other hand, bias of MODIS onboard Terra satellite shows a negative trend during both daytime and nighttime (Figs. $5 \mathrm{c}$ and d). MODIS SSTs onboard both Terra and Aqua satellites exhibited the larger RMSE during daytime rather than nighttime, but it was noticeable that RMSE of MODIS onboard Terra satellite was lower than that onboard Aqua satellite during both daytime and nighttime.

Time lag dependence of SST differences is shown in Fig. 6. Based on the passage time of the satellite, the bias varied gradually with the increase of time difference. The biases were relatively lower while the in situ observations were in the time difference of 4 hours before and after the satellite passage (top of Fig. 6). SST differences reflect larger than $\pm 3^{\circ} \mathrm{C}$ after the time difference of 8 hours. The SST differences with a time lag of less than 3 hours are shown at the bottom of Fig. 6. It is clear that the bias of MODIS SSTs varied within the range of $\pm 2^{\circ} \mathrm{C}$, SST differences were reduced by $1^{\circ} \mathrm{C}$ compared with that based on match-ups with time lag of longer than 4 hours.

As the daily variations of bias shown in Fig. 6, we thus further examined SST differences more carefully with the time lag of less than 3 hours. The scatter diagrams of MODIS and in situ SSTs are shown in Fig. 7. SST differences become smaller compared with the cases of match-ups with 24-hour time lags. Larger positive bias of Aqua daytime $\left(0.44^{\circ} \mathrm{C}\right)$ and negative bias of Terra daytime $\left(-0.41^{\circ} \mathrm{C}\right)$ were also found. RMSEs during daytime of Terra and Aqua were as low as 0.2 and $0.1^{\circ} \mathrm{C}$ respectively, in nighttime, SST differences become smaller if the time differences were shorter, as found in daytime.

\section{DISCUSSION AND CONCLUSION}

The comparison of satellite-derived SST with in situ data can be used to identify systematic errors or serious regional anomalies as it estimates really gross differences.

Table 1. Coefficients of the MCSST retrieved equations for Aqua/Terra satellites in daytime and nighttime.

\begin{tabular}{|c|c|c|c|c|c|c|c|c|c|c|}
\hline Satellite & Day/Night & Num & $a 0$ & $a 1$ & $\alpha 3.7$ & $\alpha 8.7$ & $\alpha 12$ & $\beta 3.7$ & $\beta 8.7$ & $\beta 12$ \\
\hline \multirow[t]{2}{*}{ Terra } & Day & 440 & -15.78671 & 1.06799 & 0.0 & -1.27617 & 2.90795 & 0.0 & 0.602358 & 0.5172018 \\
\hline & Night & 285 & -8.906356 & 1.03951 & -0.75022 & -0.457208 & 1.182532 & -0.757091 & 0.421995 & -0.440849 \\
\hline \multirow[t]{2}{*}{ Aqua } & Day & 371 & -12.01327 & 1.05403 & 0.0 & -1.454446 & 2.855139 & 0.0 & 0.686551 & 0.9803903 \\
\hline & Night & 207 & -0.175109 & 1.04428 & -0.520334 & -0.132179 & -0.173482 & -0.173482 & 0.319779 & 0.8426539 \\
\hline
\end{tabular}


(a) Before registration

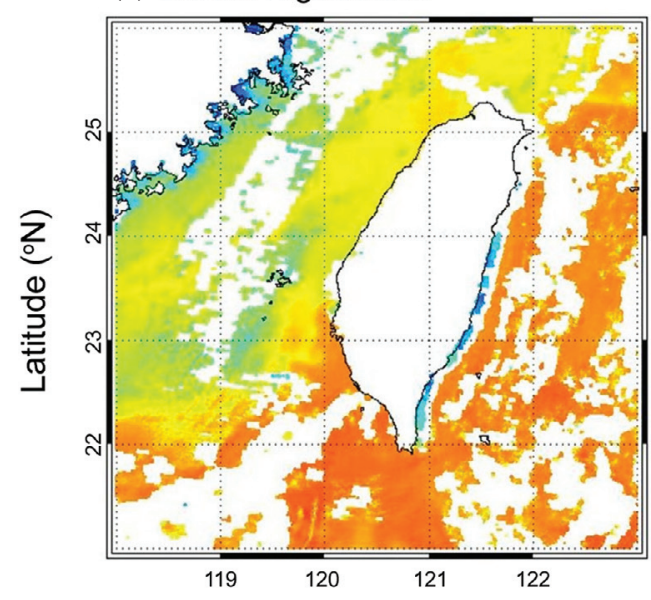

(b) After registration

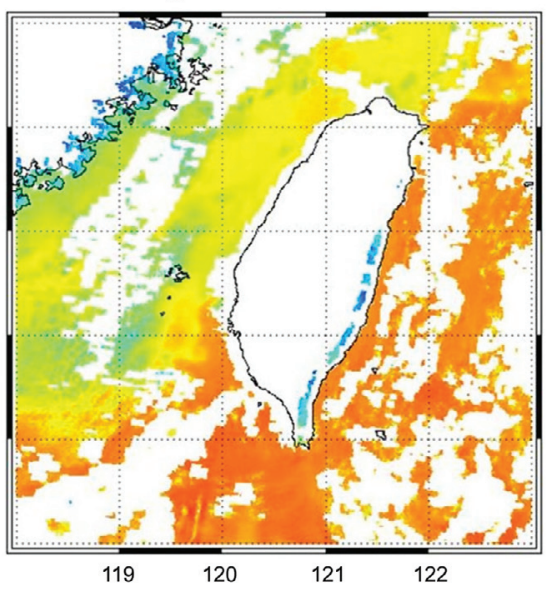

$\begin{array}{llllll}258.0 & 289.0 & 293.0 & 297.0 & 301.0 & 305.0\left({ }^{\circ} \mathrm{K}\right)\end{array}$

Fig. 3. Projecting correction of MODIS SST image, (a) before and (b) after the registration for Aqua nighttime image on 21 October 2004, 17:16 (local time).

(a) Cloud-free

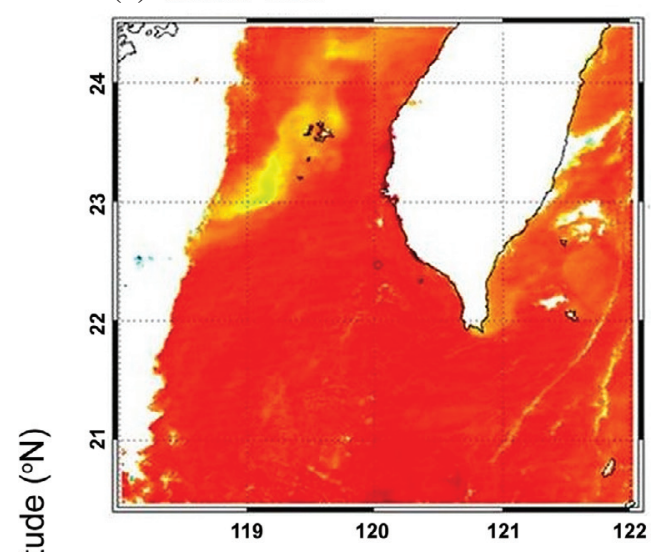

(c) Near cost

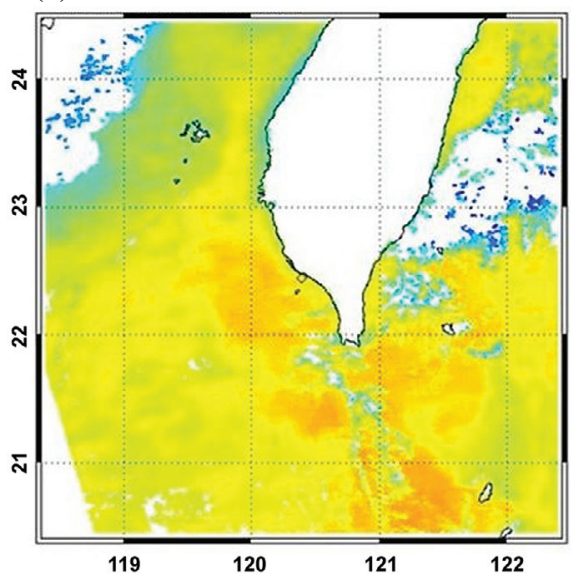

(b) Near front

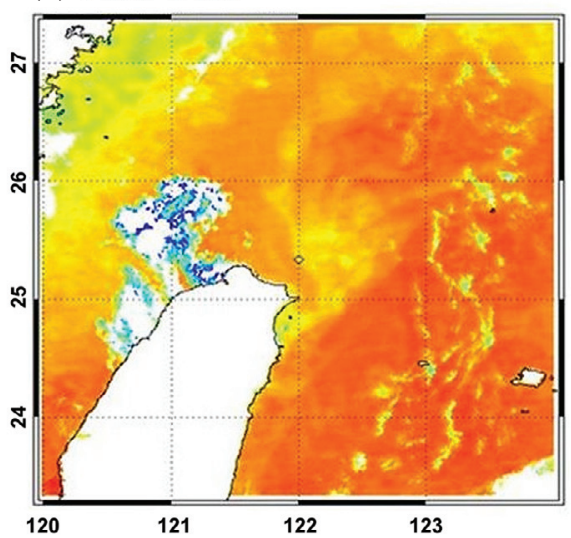

(d) Cloudy

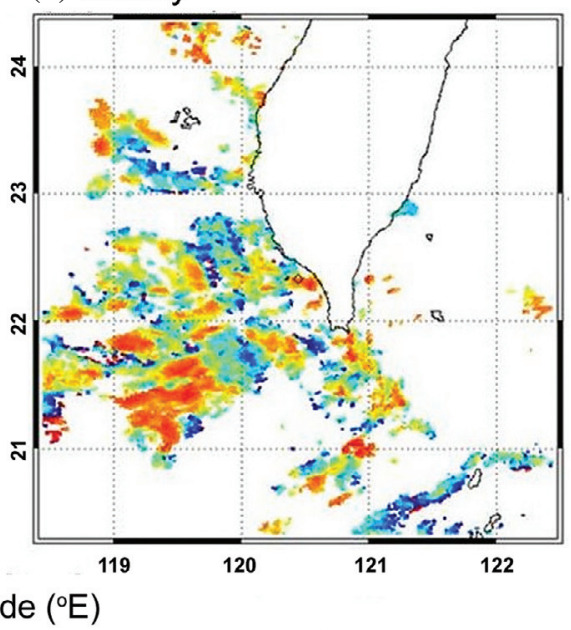

$\begin{array}{llllll}285.0 & 289.0 & 293.0 & 297.0 & 301.0 & 305.0\left({ }^{\circ} \mathrm{K}\right)\end{array}$

Fig. 4. Classification of the data match-up condition in four categories: (a) Cloud-free, (b) Near front, (c) Near coast, and (d) Cloudy (Black circle shows the CTD point). The blue dots in the images are the cloudy pixels. 

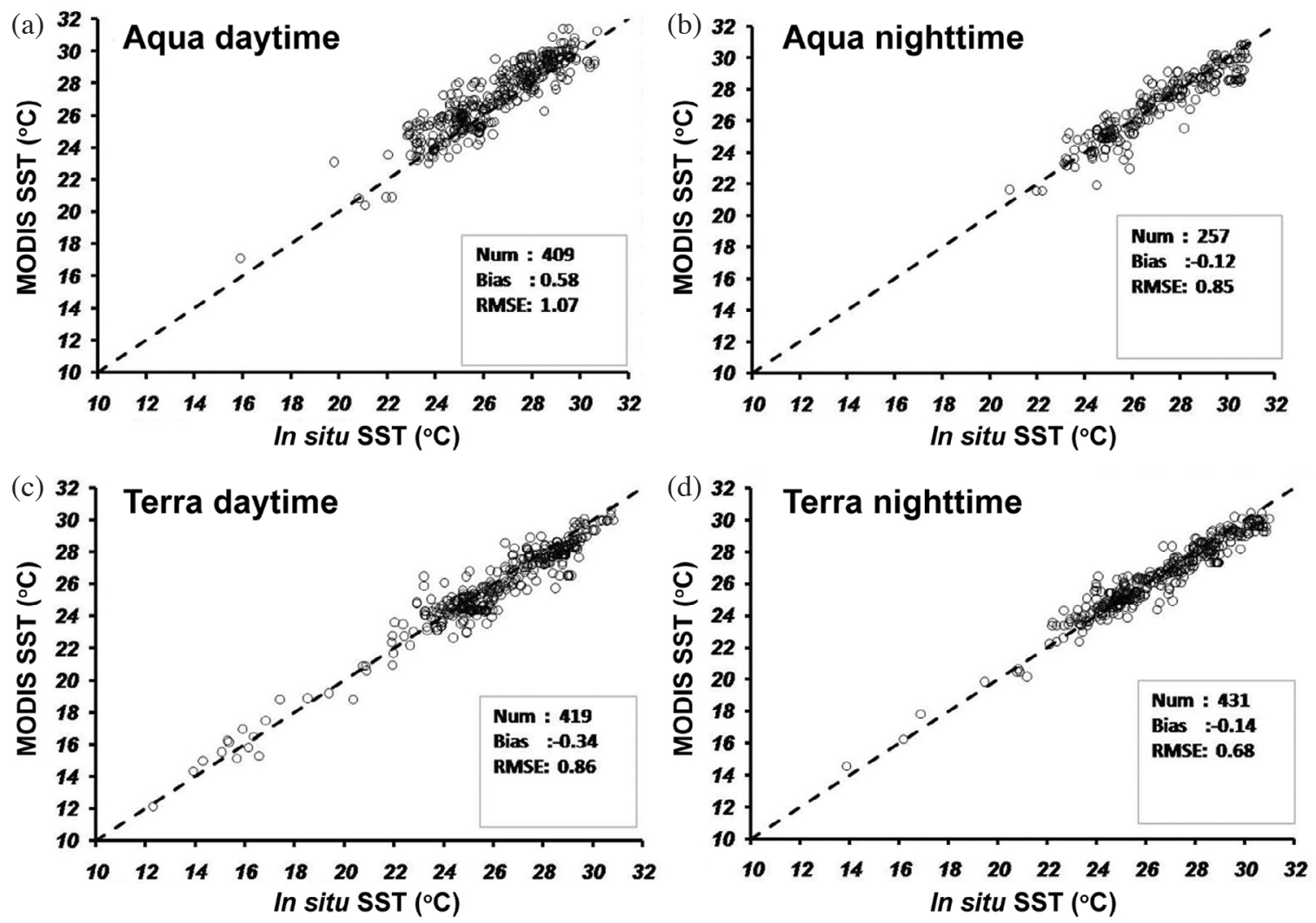

Fig. 5. Scatter diagrams of MODIS SST and in situ SST within the time difference of less than 24 hours.

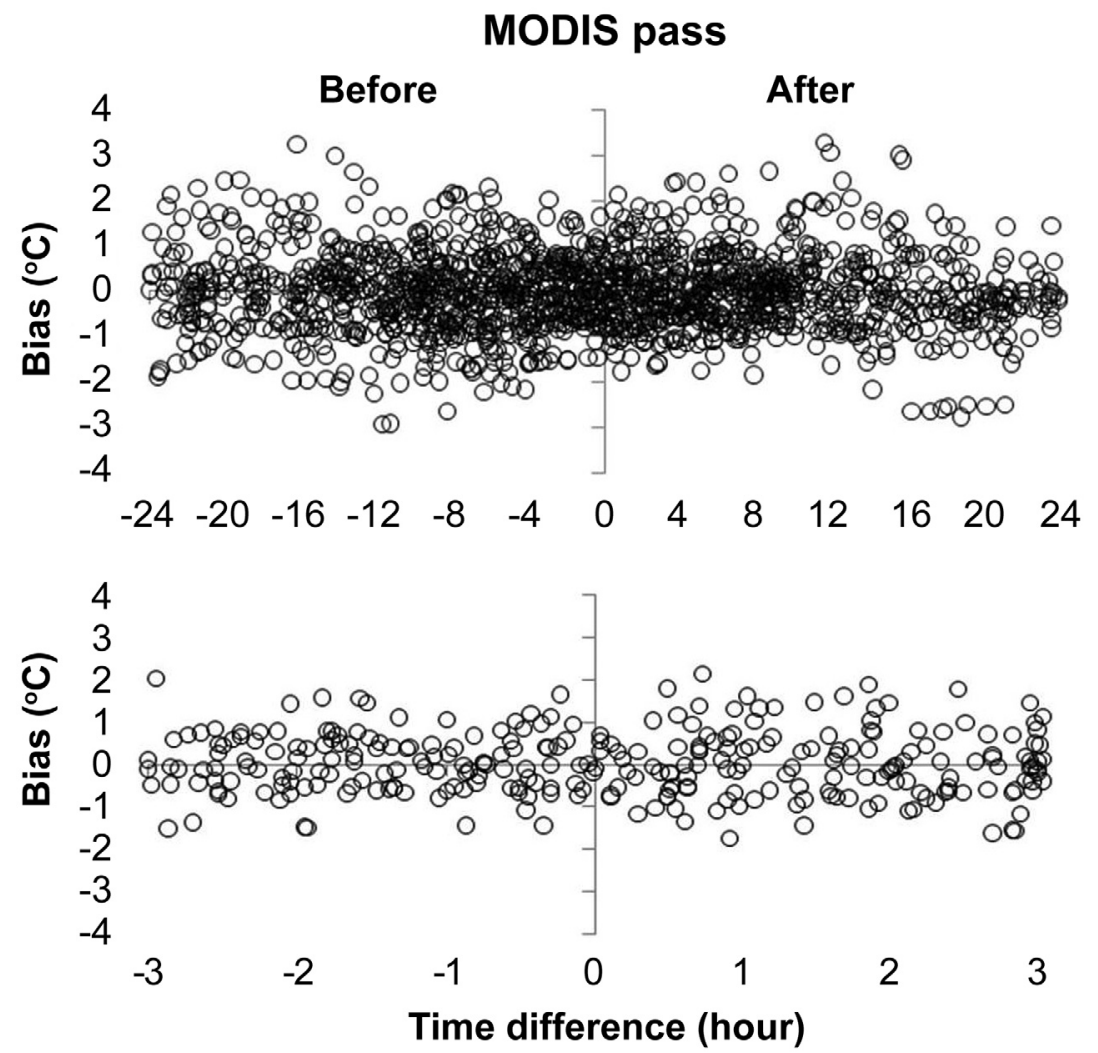

Fig. 6. SST bias (MODIS minus in situ SST) for match-up data pairs: within 24 hours (top), and within 3 hours (bottom). 

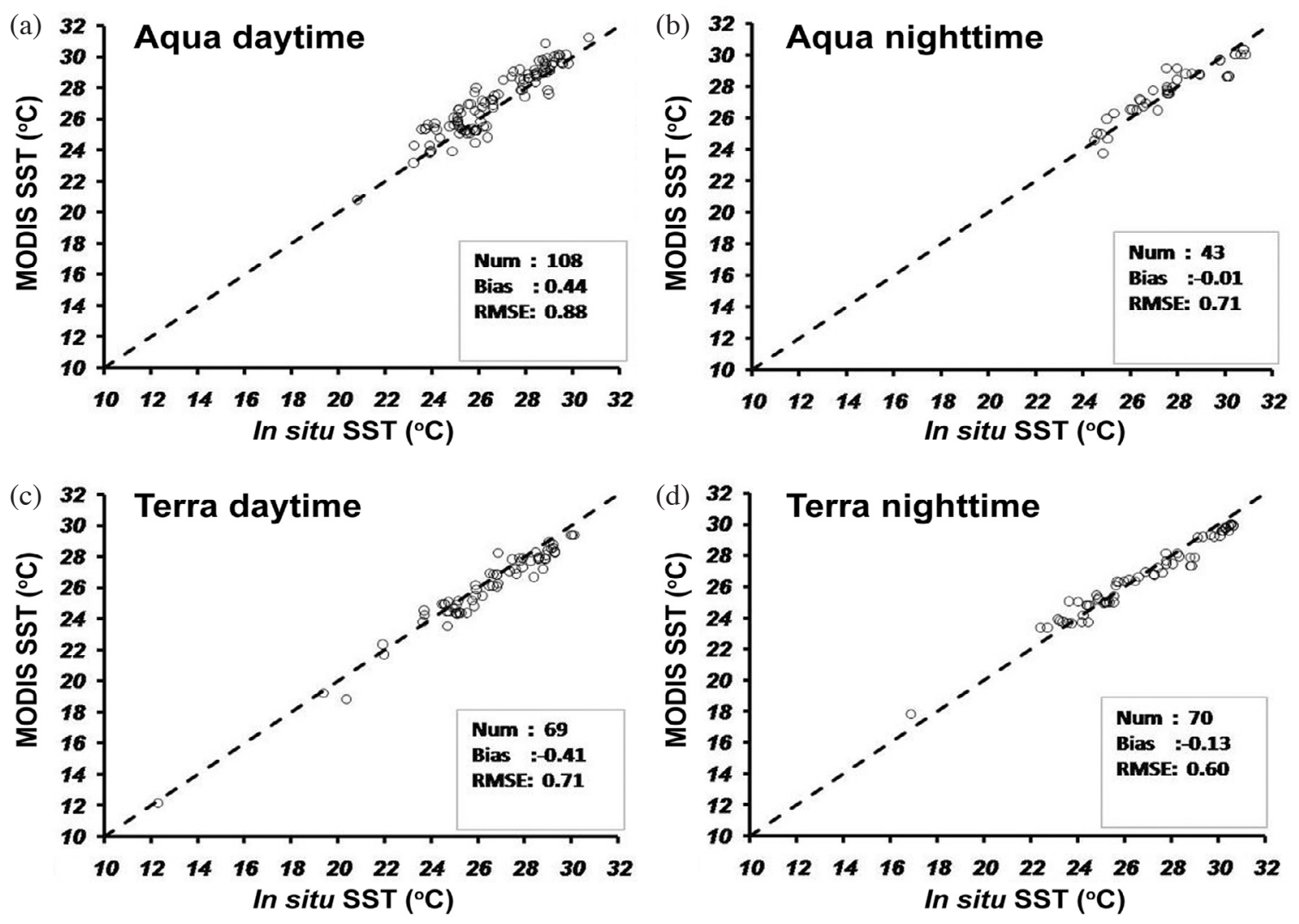

Fig. 7. Scatter diagrams of MODIS SST and in situ SST within the time difference of less than 3 hours.

The validation of MODIS SST has been carried out for the coastal waters around Taiwan. For the MODIS SST estimation with the MCSST algorithm, the bias and RMSE of match-up data taken within 24 and 3 hours are summarized in Table 2, which also include the daytime and nighttime variations of match-ups in each satellite instrument. The comparisons in within 24 hours for MODIS aboard Terra/ Aqua satellites corresponded well with in situ SST, while the biases were between -0.35 and $0.58^{\circ} \mathrm{C}$, but the RMSE being larger than $0.68^{\circ} \mathrm{C}$, while the Aqua daytime shows the largest RMSE of $1.07^{\circ} \mathrm{C}$. A small improvement is gained by restricting the time difference. When the time differences were restricted to within 3 hours both the bias and RMSE were improved more than $0.1^{\circ} \mathrm{C}$. When validating satellitederived SST, several pixels around an in situ observation point were usually averaged and matched up with the in situ SST. This study also compared the estimation errors of using 1-pixel and averaged 3 by 3 -pixel where the CTD located in the satellite image. However, Table 2 shows that the bias and RMSEs of 3 by 3-pixel were not significantly different from the 1-pixel estimation.

The diurnal variation of SST under cloud free conditions is visible by using two MODIS observations (Aqua, 12:00 to 13:00; Terra, 09:00 to 10:00). The satellite SST algorithm (Hosoda 2004) was tuned to derive water tem- perature at 1-m depth. On the other hand, the in situ data used in this study were acquired from the CTD, which provides water temperature at the depth of less than $5 \mathrm{~m}$. One of the possible causes of the temperature differences between MODIS and CTD is the reflection of surface stratifications, which are formed by solar insolation under weak wind condition (Gentemann et al. 2003). For the Aqua satellite, the bias of daytime SSTs $\left(>0.4^{\circ} \mathrm{C}\right)$ is significantly higher than that of nighttime SSTs $\left(<-0.01^{\circ} \mathrm{C}\right)$. Does the diurnal warming affect the Aqua daytime SST in the waters around Taiwan? Figure 8 shows the monthly variation of bias of each satellite in both daytime and nighttime. The biases of Aqua daytime are always positive and especially apparent from March through August (Fig. 8a) when the southwesterly monsoon is weak. During this period, lower sea surface wind speed is dominant in our study area (Jan et al. 2002; Kuo and Ho 2004). Donlon et al. (2002) pointed out under a wind threshold of $6 \mathrm{~m} \mathrm{~s}^{-1}$ diurnal heating can occur. It is likely that the larger positive biases in our result are due to the diurnal warming at the lower wind speed conditions since the SST validation can be less accurate when a diurnal warming effect is considered (Kawai and Kawamura 2002). On the other hand, the negative bias of Terra daytime was not only observed in this study, but also found in both JAXA and NASA MODIS data sets (see Table 4 of Hosoda 
et al. 2007). Our result showed a similar negative estimation error, we thus suggest that the negative bias estimation from MODIS SSTs should be related to the coefficients of SST retrieved algorithms.

Unlike the diurnal variation of Aqua satellite, Fig. 8b shows that bias of Terra daytime are usually negative in our study area. The pass time of the Terra satellite through the region is about 09:00 to 10:00. It is possible that these anomalies are due to different strength of diurnal heating in the near surface layer because the solar radiation is weaker in the morning. Gentemann et al. (2003) suggested that diurnal warming does not emerge when daily mean solar energy at the top of atmosphere is less than $132 \mathrm{~W} \mathrm{~m}^{-2}$, concurring with our result shown here. Lee et al. (2005) validated the AVHRR SSTs by CTD data in the same area and also found the diurnal variation effect on MCSST estimation. However, their bias in daytime was lower than $0.05^{\circ} \mathrm{C}$ and the RMSE was smaller than $0.67^{\circ} \mathrm{C}$. Thus, in the present study, the MODIS SSTs were not as accurate as AVHRR SST. In order to reduce the effect of diurnal warming, we estimated errors of the MCSST algorithm by restricting the match up data to within 3 hours. From the scatter plots for each satellite in both daytime and nighttime match-up sets in Fig. 7, we can see all of the comparisons showing slightly improved agreement. Even though, the RMSE of MCSST estimation in the waters around Taiwan was still higher than $0.7^{\circ} \mathrm{C}$, with the exception of the Terra nighttime $\left(0.60^{\circ} \mathrm{C}\right)$. Higher RMSE is worse than that of the western North Pacific (Hosoda et al. 2007). For the worse accuracy of MODIS SSTs in our study area as compared with that of MODIS SSTs in the North pacific and AVHRR SSTs in the waters around Taiwan, it is difficult to identify the main reason for the worse performance of MODIS SST retrieval. Due to the worse accuracy and negative bias of Terra daytime observed in our study as well as in Hosoda et al. (2007), we need more careful analysis of both satellite and in situ data in the future to calibrate the SST retrieved algorithms of MODIS in the waters around Taiwan.

In Hosoda et al. (2007), the MODIS SSTs estimated from global MCSST also showed a diurnal variation effect on the western North Pacific Ocean. They compared their result of MCSST with the estimation error of nonlinear SST algorithm (NLSST: Walton 1988). Their results showed that the quality of MODIS SST estimations in daytime was improved under the low wind speed conditions. It is noticeable that in our results, the bias and RMSE of MODIS aboard

Table 2. In situ comparison between results for Aqua/Terra satellites in daytime and nighttime within 24 and 3 hours of the satellite overpass time.

\begin{tabular}{|c|c|c|c|c|c|c|c|c|}
\hline & & & \multicolumn{2}{|c|}{ Aqua } & \multicolumn{2}{|c|}{ Terra } & \multicolumn{2}{|c|}{ Total } \\
\hline & & & $\pm 24 \mathrm{hr}$ & $\pm 3 \mathrm{hr}$ & $\pm 24 \mathrm{hr}$ & $\pm 3 \mathrm{hr}$ & $\pm 24 \mathrm{hr}$ & $\pm 3 \mathrm{hr}$ \\
\hline \multirow[t]{5}{*}{ Day } & Num & & 409 & 108 & 419 & 69 & 828 & 177 \\
\hline & Bias & 1 pixel & 0.56 & 0.44 & -0.34 & -0.41 & 0.11 & 0.11 \\
\hline & & $3 \times 3$ pixel & 0.59 & 0.42 & -0.34 & -0.41 & 0.11 & 0.10 \\
\hline & RMSE & 1 pixel & 1.07 & 0.88 & 0.86 & 0.71 & 0.97 & 0.82 \\
\hline & & $3 \times 3$ pixel & 1.06 & 0.86 & 0.86 & 0.71 & 0.96 & 0.80 \\
\hline \multirow[t]{5}{*}{ Night } & Num & & 257 & 43 & 431 & 70 & 688 & 113 \\
\hline & Bias & 1 pixel & -0.12 & -0.01 & -0.14 & -0.13 & -0.13 & -0.10 \\
\hline & & $3 \times 3$ pixel & -0.10 & 0.01 & -0.11 & -0.10 & -0.11 & -0.06 \\
\hline & RMSE & 1 pixel & 0.85 & 0.71 & 0.68 & 0.60 & 0.75 & 0.64 \\
\hline & & $3 \times 3$ pixel & 0.80 & 0.66 & 0.64 & 0.53 & 0.71 & 0.59 \\
\hline \multirow[t]{5}{*}{ Total } & Num & & 666 & 151 & 850 & 139 & 1516 & 290 \\
\hline & Bias & 1 pixel & 0.31 & 0.31 & -0.24 & -0.27 & 0.01 & 0.03 \\
\hline & & $3 \times 3$ pixel & 0.31 & 0.31 & -0.23 & -0.26 & 0.01 & 0.04 \\
\hline & RMSE & 1 pixel & 0.99 & 0.84 & 0.78 & 0.65 & 0.88 & 0.75 \\
\hline & & $3 \times 3$ pixel & 0.97 & 0.81 & 0.76 & 0.63 & 0.86 & 0.73 \\
\hline
\end{tabular}



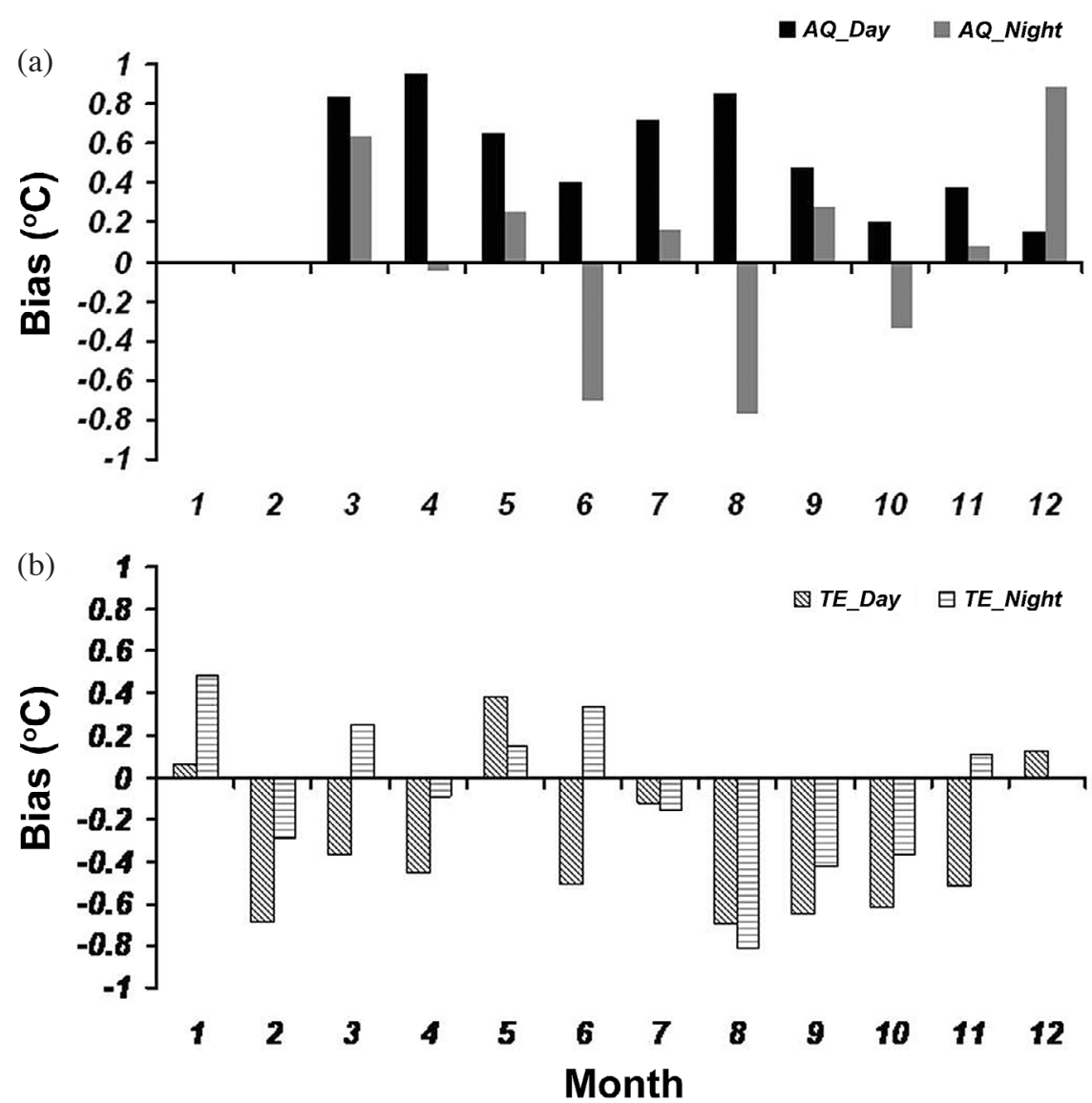

Fig. 8. Monthly bias variations of (a) Aqua and (b) Terra. X axis: time scale of month; Y axis: bias of MODIS SST onboard Aqua (AQ) and Terra (TE).

Aqua/Terra satellites are less accurate than that of the above study. It is suggested that the large positive bias and RMSE of Aqua daytime are not only due to the diurnal variation but also to the estimation error of global MCSST algorithm in the waters around Taiwan. Walton (1988) developed nonlinear SST algorithm to overcome some weaknesses in the MCSST algorithm. Finally, it is suggested that the nonlinear SST algorithm should be adapted to the MODIS SST estimation for comparison with MCSST accuracy in the future.

\section{SUMMARY}

The present study validated MODIS near real time SST images in the regional waters around Taiwan. Projection error and quality check were carefully controlled by visual inspection. Using higher-resolution (1 km) MODIS images of Aqua and Terra satellites, we produced 1516 match-up data sets of MODIS measurements and in situ SST. The MCSST algorithms with the regional coefficients for each satellite were examined in detail using a match-up data set. Although SST characteristics are different in costal waters and the open ocean, the MODIS-derived SST shows good agreement with in situ SST. To synthesize each satellite, MCSST has a bias of $0.03^{\circ} \mathrm{C}$ with RMSE of $0.75^{\circ} \mathrm{C}$.

Effects of diurnal warming on two MODIS data observed in the morning (Terra) and noon (Aqua) in our study region were investigated using the match up data within 3 hours and discussed with previous studies in the global ocean and adjacent seas. The ocean surface is warm at noon but cool in the morning. The RMSE of higher than $0.7^{\circ} \mathrm{C}$ in Aqua and Terra daytime may be attributed to the large positive bias of Aqua $\left(0.43^{\circ} \mathrm{C}\right)$ and negative bias of Terra $\left(-0.41^{\circ} \mathrm{C}\right)$. It is noticeable that the sources of error in estimating SST are due to the surface stratification caused by solar radiation. Validation of satellite-derived SST estimation is a continuing requirement for researchers of ocean science as demands on measurement accuracy increase. In the future it will be necessary for other surface-based measurements to provide bulk SST for more useful validation of satellite-derived SST products under all surface conditions with high temporal frequency. Moreover, the quality of regional estimation should be further improved by using the NLSST algorithm or developing new regional coefficients. 
Acknowledgements This study was supported by a research grant awarded by the Global Center of Excellence (GCOE program) at Tohoku University, Japan, and the Taiwan Ocean Research Institute (97-TORI-003), National Applied Research Laboratories, Taiwan. The authors would also express their appreciation to Professor Chang-tai Shih of National Taiwan Ocean University for his helpful advice on this manuscript. And the authors also appreciate Dr. Teruhisa Shimada, Dr. Hui-Ling Qin and Mr. Yuong-Liang Wei of Tohoku University for their technical support.

\section{REFERENCES}

Chang, Y., H. T. Liao, M. A. Lee, J. W. Chan, W. J. Shieh, K. T. Lee, G. W. Wang, and Y. C. Lan, 2008: Multisatellite observation on upwelling after the passage of Typhoon Hai-Tang in the southern East China Sea. Geophys. Res. Lett., 35, L03612, doi: 10.1029/2007GL 032858. [Link]

Chuang, W. S., 1985: Dynamics of subtidal flow in the Taiwan Strait. J. Oceanogr. Soc. Jpn., 41, 65-72, doi: 10.1007/BF02109175. [Link]

Donlon, C. J., P. J. Minnett, C. Gentemann, T. J. Nightingale, I. J. Barton, B. Ward, and M. J. Murray, 2002: Toward improved validation of satellite sea surface skin temperature measurements for climate research. $J$. Climate, 15, 353-369, doi: 10.1175/1520-0442(2002)0 15<0353:TIVOSS >2.0.CO;2. [Link]

Gentemann, C. L., C. J. Donlon, A. Stuart-Menteth, and F. J. Wentz, 2003: Diurnal signals in satellite sea surface temperature measurements. Geophys. Res. Lett., 30, 1140, doi: 10.1029/2002GL016291. [Link]

Goodrum, G., K. B. Kidwell, and W. Winston, 2000: NOAA KLM User's guide - September 2000 revision, Technical report. Online version http://ww2.nsdc.noaa. gov $/ \mathrm{docs} / \mathrm{klm} /$.

Hosoda, K., 2004: Version up of MODIS near-real-time SST processing. Online document available at: http:// suzaku.eorc.jaxa.jp/GLI/ocean/modis nrt/modis sst 200409.pdf. (in Japanese)

Hosoda, K., H. Murakami, F. Sakaida, and H. Kawamura, 2007: Algorithm and validation of sea surface temperature observation using MODIS sensors aboard terra and aqua in the western North Pacific. J. Oceanogr.,
63, 267-280, doi: 10.1007/s10872-007-0027-4. [Link]

Jan, S., J. Wang, C. S. Chen, and S. Y. Chao, 2002: Seasonal variation of the circulation in the Taiwan Strait. J. Mar. Syst., 35, 249-268, doi: 10.1016/S0924-7963 (02)00130-6. [Link]

Kawai, Y. and H. Kawamura, 2002: Evaluation of the diurnal warming of sea surface temperature using satellitederived meteorological data. J. Oceanogr., 58, 805814, doi: 10.1023/A:1022867028876. [Link]

Kuo, N. J. and C. R. Ho, 2004: ENSO effect on the sea surface wind and sea surface temperature in the Taiwan Strait. Geophys. Res. Lett., 31, L13309, doi: 10.1029/ 2004GL020303. [Link]

Lee, M. A., Y. Chang, F. Sakaida, H. Kawamura, C. H. Cheng, J. W. Chan, and I. Huang, 2005: Validation of satellite-derived sea surface temperatures for waters around Taiwan. Terr. Atmos. Ocean. Sci., 16, 11891204.

Li, C., J. Hu, S. Jan, Z. Wei, G. Fang, and Q. Zheng, 2006: Winter-spring fronts in Taiwan Strait. J. Geophys. Res., 111, C11S13, doi: 10.1029/2005JC003203. [Link]

McClain, E. P., W. G. Pichel, and C. C. Walton, 1985: Comparative performance of AVHRR-based multichannel sea surface temperatures. J. Geophys. Res., 90, 1158711601, doi: 10.1029/JC090iC06p1 1587. [Link]

Sakaida, F. and H. Kawamura, 1992: Estimation of sea surface temperature around Japan using the Advanced Very High Resolution Radiometer (AVHRR)/ NOAA-11. J. Oceanogr., 48, 179-192, doi: 10.1007/ BF02239004. [Link]

Shenoi, S. C., 1999: On the suitability of global algorithms for the retrieval of SST from the north Indian Ocean using NOAA/AVHRR data. Int. J. Remote Sens., 20, 11-29, doi: 10.1080/014311699213578. [Link]

Walton, C. C., 1988: Nonlinear multichannel algorithms for estimating sea surface temperature with AVHRR satellite data. J. Appl. Meteorol., 27, 115-124, doi: 10.11 75/1520-0450(1988)027<0115:NMAFES>2.0.CO;2. [Link]

Wan, Z., 2002: Estimate of noise and systematic error in early thermal infrared data of the Moderate Resolution Imaging Spectroradiometer (MODIS). Remote Sens. Environ., 80, 47-54, doi: 10.1016/S0034-4257(0 1)00266-8. [Link] 